\title{
Journal of Applied Polymer Science
}

Volume 133, Issue 34

10 September 2016

\section{http://onlinelibrary.wiley.com/doi/10.1002/app.43823/full}

DOI: $10.1002 / a p p .43823$

\section{Improvement of the impact strength of ethylene-propylene random copolymers by nucleation}

Zsuzsanna Horváth ${ }^{1,2}$, Alfréd Menyhárd ${ }^{1,2}$, Petar Doshev ${ }^{3}$, Markus Gahleitner ${ }^{3}$, David Friel ${ }^{3}$, József Varga ${ }^{1,2}$ and Béla Pukánszky ${ }^{1,2}$

${ }^{1}$ Laboratory of Plastics and Rubber Technology, Budapest University of Technology and Economics, H-1111 Budapest, Müegyetem rakpart 3., Hungary

${ }^{2}$ Institute of Materials Science and Environmental Chemistry, Research Centre for Natural Sciences, Hungarian Academy of Sciences, H-1117 Budapest, Magyar Tudósok Körútja 2., Hungary

${ }^{3}$ Borealis Polyolefine GmbH, St.-Peter-Strasse 25, A-4021 Linz, Austria

(Correspondance to Alfréd Meynhárd (Fax: 0036-1-463-3474, E-mail: amenyhard@mail.bme.hu))

Running head: Molecular architecture, nucleation and impact resistance

\section{ABSTRACT}

Five ethylene-propylene random copolymers were nucleated with two soluble nucleating agents. Ethylene content changed between 1.7 and $5.3 \mathrm{wt} \%$, while nucleating agent content was adjusted according to the solubility of the additive. It changed from 0 to 5000 ppm for the sorbitol (1,2,3-tridesoxy-4,6:5,7-bis-O-[(4-propylphenyl) methylene]-nonitol) and from 0 to $500 \mathrm{ppm}$ for the trisamide compound (1,3,5-benzene-trisamide) used. Crystalline structure was analyzed in detail by various methods (DSC, XRD and SEM). Mechanical properties were characterized by tensile and instrumented impact measurements. The results 
showed that most properties changed moderately upon nucleation, but impact resistance increased considerably. Spherulitic structure was not detected, but a microcrystalline structure formed instead in the presence of the soluble nucleating agents used. The large increase of impact resistance could not be related directly to changes in crystalline morphology. On the other hand, local rearrangement of morphology was detected by XRD and SEM analysis including an increase of lamella thickness, crystal orientation and the formation of shishkebab structures in the core of the injection molded specimens. A small increase in the $\gamma$ phase content of PP was also observed. These changes increased crack propagation energy considerably leading to the large improvement observed in impact resistance. Although the phenomenon could be related to ethylene content, differences in molecular weight also helped to explain the extent of the changes.

KEYWORDS: polypropylene, impact resistance, nucleation, crystalline structure, $\gamma$ modification, lamella thickness, crack propagation

\section{INTRODUCTION}

Polypropylene (PP) is a commodity polymer used in increasing amounts in all sectors of industry. Its growth rate is one of the largest among all polymers and this results from advantageous properties and extremely good price/performance ratio ${ }^{1}$. One of the main advantages of polypropylene is its versatility; its molecular structure can be varied by the proper selection of the catalyst system and reactor technology in a very wide range ${ }^{2}$ and properties can be further modified by blending or using reinforcements ${ }^{3}$. PP homopolymers are stiff materials and special grades can compete even with engineering polymers these 
days $^{4}$, while the low temperature impact resistance of random copolymers and reactor blends may exceed that of high impact polystyrene ${ }^{5-7}$. The properties of crystalline polymers are determined by their crystalline structure, which is controlled by the molecular architecture of the polymer chains and by crystallization conditions. A high number of parameters influence the molecular and crystalline structure of PP thus complicated relationships exist between structure and their properties. As a consequence, general correlations between structure and properties are not known and development is usually done on trial and error basis.

The main goal of most developments today is to produce materials with balanced properties. Usually large stiffness and fracture resistance are required for structural applications and often also the optical properties of the material are of importance. However, large stiffness and impact resistance are very difficult to achieve simultaneously, the increase of the former is usually accompanied by a decrease in the second property. The stiffness of polypropylene homopolymers may reach $2.4-2.5 \mathrm{GPa}^{4,8}$, but their impact resistance is very poor and becomes even worse at temperatures below $0{ }^{\circ} \mathrm{C}$. Various strategies have been developed to increase the low temperature impact resistance of PP including the changing of polymerization conditions, multi-phase copolymerization and blending 9 .

The practical importance of fracture resistance is clearly shown also by the number of papers related to it, where single-phase materials like homopolymers ${ }^{10,11}$ and random copolymers ${ }^{12,13}$ are normally discussed separately from multi-phase impact copolymers ${ }^{14}$. In the former case, the crystalline PP phase can be modified to improve its toughness, while the incorporation of elastomer particles is decisive in the latter. For homopolymers, Salazar et al. ${ }^{11}$ for example showed that peroxide vis-breaking of polypropylene results in decreased molecular weight, increased spherulite size and inferior fracture resistance. $\mathrm{Na}$ and coworkers ${ }^{15}$ found that the annealing of injection molded isotactic PP homopolymer resulted in structural rearrangement and considerable toughening, as shown already earlier ${ }^{16}$. In the 
case of random copolymers with ethylene, toughness increases with comonomer content ${ }^{12}$ and annealing can also have the same result ${ }^{17}$.

Multi-phase copolymers are of more complex nature and are, while offering high impact resistance in a wide temperature range, disadvantageous in terms of transparency and gloss. Van Reenen and Basson ${ }^{18}$ characterized an impact PP grade by temperature rising elution fractionation (TREF), then they selectively removed certain components and studied the effect of molecular composition on the properties of their PP. They observed that the degree of phase separation and crystalline morphology varied considerably as a result, which led to changing hardness and predictably also modified impact resistance. Other groups prepared blends from PP and poly(ethylene glycol) (PEG) and studied the effect of processing conditions $^{19}$ as well as annealing ${ }^{20}$ on structure and properties. Annealing was shown to change phase structure in PP/PEG blends resulting in a large increase in toughness. These results indicate that dispersed structure influence the impact resistance of PP polymers considerably.

Usually, nucleating agents are also used for influencing the properties of iPP grades. Normally, $\alpha$-nucleation will increase stiffness, but results in a reduction of impact resistance for both single- and multi-phase $\mathrm{PP}^{21}$, while $\beta$-nucleation generally reduces stiffness and increases toughness ${ }^{22,23}$. In both cases, however, polymer structure plays a decisive role for the actual effects. Toughness increase by $\alpha$-nucleation has been demonstrated for high-flow PP homopolymers ${ }^{10}$, for blends with external elastomers ${ }^{24}$ and for heterophasic ethylenepropylene copolymers with specific elastomer design ${ }^{25}$. No such data, which reports the enhancement of impact resistance by specific nucleation, have been shown for random copolymers so far.

In a large project with the aim of finding general correlations among molecular 
structure, crystalline morphology and various properties of PP, a series of PP homopolymers, random copolymers and reactor blends were prepared and thoroughly characterized. Their crystalline structure was modified by nucleation in order to create materials with balanced properties. Clear correlation was found between the molecular structure of the polymers and the optical as well as mechanical properties of the product ${ }^{26,27}$. The haze values achieved were related also to the chemical structure of the soluble nucleating agents used ${ }^{28}$. The relationship among the molecular structure of the polymers, crystalline morphology, its modification by nucleation and impact resistance are discussed in this communication.

\section{EXPERIMENTAL}

Five different polypropylene samples were used in the study, all of them being ethylenepropylene random copolymers based on Ziegler-Natta type catalysts supplied by Borealis Polyolefine GmbH. Melt flow rate (ISO 1133, $230{ }^{\circ} \mathrm{C}, 2.16 \mathrm{~kg}$ ) changed in a wide range between 1.5 and $15 \mathrm{~g} / 10 \mathrm{~min}$, while the ethylene content varied between 1.7 and $5.3 \mathrm{wt} \%$ as determined by ${ }^{13} \mathrm{C}$-NMR spectroscopy. The basic molecular characteristics of the polymers used are compiled in Table 1. The polymers are identified according to their composition; the abbreviation applied contains ten times their ethylene content. Accordingly R 21 was prepared with $2.1 \mathrm{wt} \%$ ethylene as comonomer. Molecular architecture, i.e. the regularity of the chains, was characterized by the stepwise isothermal segregation technique (SIST) ${ }^{29}$. By chain regularity we understand here the isotactic run length, i.e. the average length of the chain containing isotactic monomer units and not interrupted by a stereodefect or a comonomer unit. 
Table 1 Molecular characteristics of the polymers used in the study

\begin{tabular}{|c|c|c|c|c|c|c|}
\hline Polymer & Et content & I run length ${ }^{\mathrm{a}}$ & Molecul & $\mathrm{kg} / \mathrm{mol}$ ) & $M_{w} / M_{n}$ & MFR \\
\hline & $(\mathrm{wt} \%)$ & (m.u.) & $M_{n}$ & $M_{w}$ & & $(\mathrm{~g} / 10 \mathrm{~min})$ \\
\hline $\mathrm{R} 17$ & 1.7 & 33.9 & 77 & 211 & 2.7 & 8.0 \\
\hline $\mathrm{R} 21$ & 2.1 & 41.0 & 40 & 217 & 5.4 & 14.0 \\
\hline $\mathrm{R} 27$ & 2.7 & 50.3 & 44 & 195 & 4.5 & 15.0 \\
\hline R42 & 4.2 & 32.1 & 85 & 317 & 3.7 & 1.5 \\
\hline R53 & 5.3 & 29.4 & 60 & 195 & 3.2 & 12.0 \\
\hline
\end{tabular}

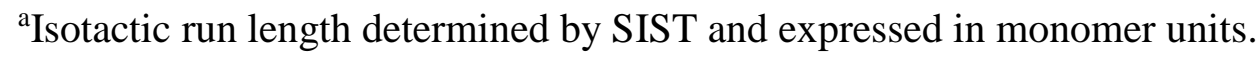

The respective SIST experiments were carried out between 160 and $100{ }^{\circ} \mathrm{C}$ using a Perkin Elmer DSC 7 apparatus with a sample mass of 3-5 $\mathrm{mg}$. After the elimination of thermal and mechanical history at $220{ }^{\circ} \mathrm{C}$ for $5 \mathrm{~min}$, the samples were cooled down to $160{ }^{\circ} \mathrm{C}$ at a rate of $80{ }^{\circ} \mathrm{C} / \mathrm{min}$ and held there for three hours. Subsequently, the samples were cooled to the next crystallization temperature $\left(150{ }^{\circ} \mathrm{C}\right)$ and kept there for another three hours. Each temperature ramp took three hours and each step was $10^{\circ} \mathrm{C}$. After the final crystallization step at $100{ }^{\circ} \mathrm{C}$ the samples were re-heated again at a rate of $10^{\circ} \mathrm{C} / \mathrm{min}$ and melting traces were recorded.

Properties were modified by nucleation ${ }^{30}$. Two soluble nucleating agents, i.e. clarifiers, were added to the polymers in different amounts according to their solubility. 1,2,3-tridesoxy- 
4,6:5,7-bis-O-[(4-propylphenyl) methylene]-nonitol, a sorbitol type clarifier (Millad NX 8000, Milliken, USA), was applied at 0, 1000, 2000, 3000, 4000 and 5000 ppm, while the trisubstituted 1,3,5-benzene-trisamide compound ${ }^{31,32}$ (XT 386, BASF, Germany), was added at $0,50,100,150,200$ and $500 \mathrm{ppm}$ to the polymers.

The stabilizers and the nucleating agents were homogenized with the polymer in a Henschel FM/A10 high speed mixer at $700 \mathrm{rpm}$ for $5 \mathrm{~min}$. The blend was melt compounded in a Brabender DSK 42/7 twin screw compounder at $50 \mathrm{rpm}$ and $200,220,230,230{ }^{\circ} \mathrm{C}$ set temperatures. The compound was injection molded to $4 \mathrm{~mm}$ thick tensile bars using a Demag IntElect 50/330-100 machine at $200-210-220-230{ }^{\circ} \mathrm{C}$ zone and $40{ }^{\circ} \mathrm{C}$ mold temperatures. Injection rate was $20 \mathrm{~mm} / \mathrm{s}$, holding pressure 500 bar and holding time $15 \mathrm{~s}$.

The melting and crystallization characteristics of the samples were determined by differential scanning calorimetry (DSC) using a Perkin Elmer DSC 7 equipment. 3-5 mg samples were heated to $220{ }^{\circ} \mathrm{C}$ at $10{ }^{\circ} \mathrm{C} / \mathrm{min}$ heating rate, kept there for $5 \mathrm{~min}$ to erase thermal history and then cooled down to $50{ }^{\circ} \mathrm{C}$ with the same rate to record crystallization characteristics. After 1 min holding time the samples were heated again to $200{ }^{\circ} \mathrm{C}$ at 10 ${ }^{\circ} \mathrm{C} /$ min heating rate to determine melting temperature and the heat of fusion. The distribution and average thickness of the lamellae were calculated from the second heating run ${ }^{33}$. The crystalline structure of the neat and nucleated polymers was studied by wide angle X-ray diffraction. XRD patterns were recorded with a Phillips PW 1830/PW 1050 equipment with $\mathrm{CuK} \alpha$ radiation at $40 \mathrm{kV}$ and $35 \mathrm{~mA}$ anode excitation between 3 and $30^{\circ} 2 \theta$ angles.

Tensile testing was carried out with an Instron 5566 type machine according to the ISO 527 standard at $23{ }^{\circ} \mathrm{C}$ and $50 \% \mathrm{RH}$. Stiffness was determined at $0.5 \mathrm{~mm} / \mathrm{min}$, while other tensile characteristics like yield stress, yield strain, tensile strength and elongation-at-break at $50 \mathrm{~mm} / \mathrm{min}$ cross-head speed and $115 \mathrm{~mm}$ gauge length. Impact resistance was determined on 
notched Charpy specimens according to the ISO 179 standard with a $1 \mathrm{~J}$ hammer at $2.9 \mathrm{~m} / \mathrm{s}$ rate and $2 \mathrm{~mm}$ notch depth. Instrumented impact testing was carried out using a Ceast Resil 5.5 instrument with a $4 \mathrm{~J}$ hammer.

Phase morphology, and the structure of the materials generally, were studied by scanning electron microscopy using a JEOL JSM 6380 LA apparatus. Micrographs were recorded on cryo-cut surfaces created at $-100{ }^{\circ} \mathrm{C}$ and etched with $1 \mathrm{wt} \% \mathrm{KMnO}_{4}$ solution for 60 min. Slices were cut both from the skin and the core section of the injection molded specimens. DMA was done using samples with 20 x 6 x $1 \mathrm{~mm}$ dimensions between -120 and $200{ }^{\circ} \mathrm{C}$ at $2{ }^{\circ} \mathrm{C} / \mathrm{min}$ heating rate in $\mathrm{N}_{2}$ atmosphere using a Perkin Elmer Pyris Diamond DMA apparatus. The measurements were carried out in tensile mode at $1 \mathrm{~Hz}$ frequency and $10 \mu \mathrm{m}$ deformation.

\section{RESULTS AND DISCUSSION}

The results are presented in several sections. First, various aspects of crystalline structure are discussed together with their possible influence on impact resistance. The effect of nucleation on properties is shown next, followed by correlations between structure and properties. The fracture process and morphology are analyzed in the last sections offering a possible explanation for the observed, large increase in impact strength.

\section{Structure}

Polypropylene, like all crystalline polymers has a hierarchical structure. Its properties are determined by various parameters of this structure the most important being crystal modification, crystallinity, lamella thickness, spherulite size and the number of tie molecules. 
Nucleation may change all of these structural parameters thus the establishment of structureproperty correlations is extremely difficult. The crystal modification of the samples ${ }^{34}$ changes only slightly, but characteristically in our study; all investigated materials crystallize predominantly in the monoclinic $\alpha$-modification, but traces of the $\beta$ form and some $\gamma$ modification also form as shown by XRD measurements ${ }^{35}$. Nucleation usually increases the temperature of crystallization and often also the heat of crystallization; the former is related to lamellar thickness, as thicker lamellae grow at higher temperatures, while the latter is related to crystallinity. The peak temperature of crystallization $\left(T_{c p}\right)$ is plotted as a function of nucleating agent content in Fig. 1 for the five polymers studied. $T_{c p}$ increases with increasing nucleating agent content indeed, but not monotonously; slowly at first and much faster at an intermediate concentration range. The temperature of crystallization reaches a saturation value at large nucleating agent content. The characteristic correlation is the result of the solubility of the nucleating agent in the polymer. Both sorbitol and trisamide type nucleating agents dissolve in PP in a certain amount and they do not nucleate the polymer at these concentrations, nucleation starts only above the solubility limit as already shown for PP homopolymers ${ }^{36}$.

Although only the correlation obtained with the sorbitol type nucleating agent is presented in Fig. 1, the relationship is the same when the trisamide compound is used, only the concentration range is different, because of its smaller critical concentration. According to earlier studies sorbitol derivatives act only above $1500 \mathrm{ppm}^{36}$, while trisamide based nucleating agents are already active above $100-300 \mathrm{ppm}^{31}$. It is interesting to note that the effect of solubility is smaller, but the efficiency of nucleation is larger in the copolymers containing more ethylene than for those with small comonomer content. 


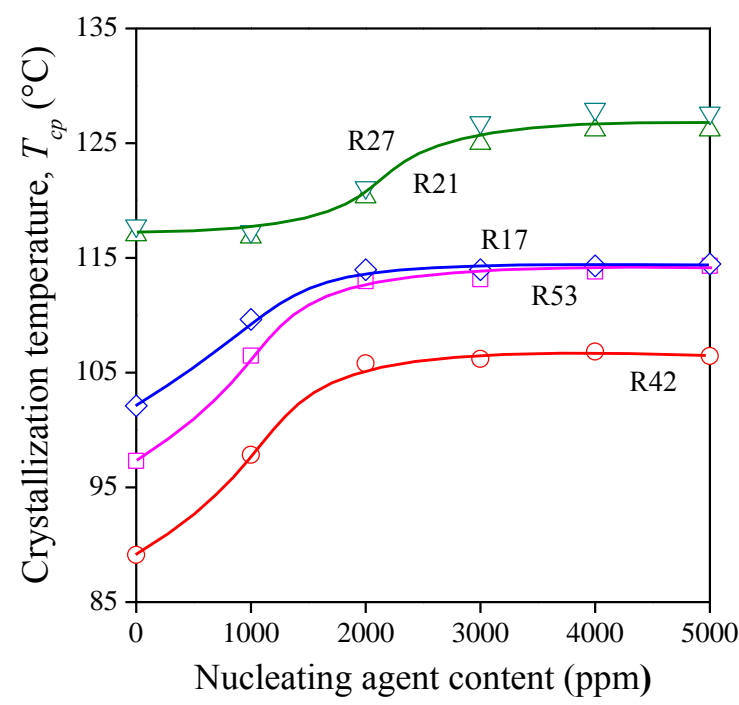

Fig. 1 Effect of the molecular structure of the polymer and nucleation on the peak temperature of crystallization of PP random copolymers containing the sorbitol clarifier. Symbols: $(\square) \mathrm{R} 53,(\bigcirc) \mathrm{R} 42,(\nabla) \mathrm{R} 27,(\triangle) \mathrm{R} 21,(\diamond) \mathrm{R} 17$

Accordingly, $T_{c p}$ increases by $8{ }^{\circ} \mathrm{C}$ for the polymer with the small (R21, R27) and by 18 ${ }^{\circ} \mathrm{C}$ for grades with large ethylene content (R42). The $\mathrm{R} 17$ polymer represents a certain transition between the two classes of polymers showing limited effect of solubility in spite of its small ethylene content. However, we must emphasize that its isotactic run length is small (see Table 1) justifying this behavior and showing that ethylene content alone does not determine crystallization and crystallinity, even if this is the predominant factor. The expected general tendency can be seen in the figure, crystallization temperature decreases with increasing ethylene content and decreasing isotactic run length. The unexpected behavior of R17 and R53 can be explained by the complex effect of other parameters like MFR and MWD, which also influence crystallization behavior. 


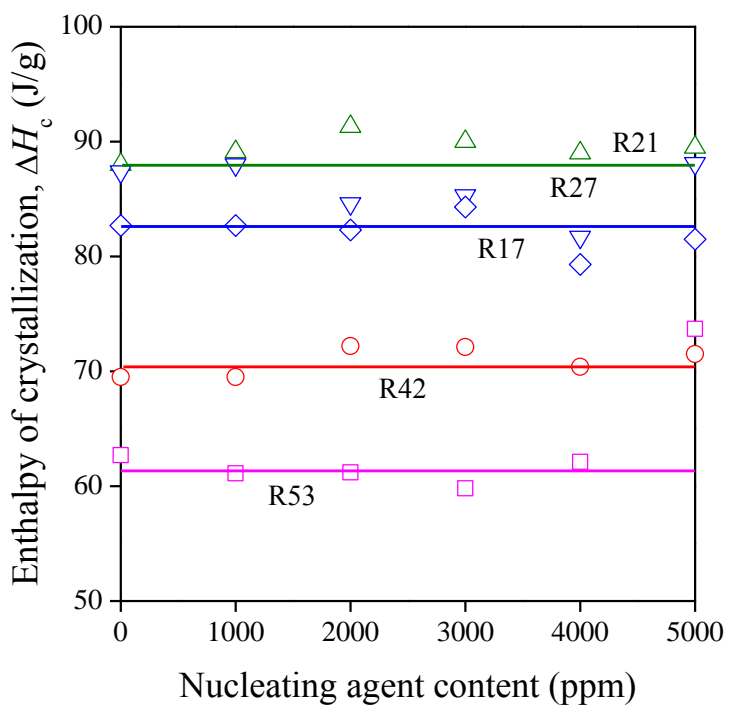

Fig. 2 Enthalpy of crystallization plotted against the concentration of the sorbitol nucleating agent for polymers with various ethylene contents. Symbols: ( $\square$ ) R53, $(\bigcirc) \mathrm{R} 42,(\nabla) \mathrm{R} 27,(\triangle) \mathrm{R} 21,(\diamond) \mathrm{R} 17$

The enthalpy of crystallization proportional to crystallinity is plotted against the concentration of the nucleating agent in Fig. 2. Crystallinity is practically constant in all five polymers, which often occurs in the case of copolymers, and depends basically only on chain regularity (ethylene content) $)^{12}$. However, the exclusive role of comonomer content must be treated with care. Other aspects of chain structure must also play a role here, since we cannot establish a linear correlation between crystallinity or crystallization temperature and ethylene content shown by the behavior of the R17 sample.

We have not discussed the changes in and the possible role of spherulite size and the number of tie molecules yet. Spherulites cannot be detected in polypropylenes containing soluble nucleating agents, as usually a microcrystalline structure forms in their presence ${ }^{36,37}$. The direct determination of the number of tie molecules is difficult, if not impossible, and their number is frequently assumed to be proportional to molecular mass and/or lamella 
thickness $^{22,38-43}$, although more data are available for polyethylene on this question ${ }^{44}$. In further discussion we do not consider these factors as ones significantly influencing crystalline structure and properties. Detailed XRD study confirmed the results obtained by thermal analysis (DSC), but additional information was also obtained by these techniques on crystal modification and lamella orientation as well as on the effect of nucleation on these factors. Nevertheless, the relatively small changes in crystalline structure would suggest similarly moderate modifications in mechanical properties.

\section{Properties}

The various properties of polypropylene are determined by different aspects of crystalline structure. Optical properties depend mainly on nucleus density controlling the size of the supermolecular units ${ }^{36}$. Stiffness was shown to be determined by the combined effect of crystallinity and lamella thickness ${ }^{21,27,45}$, while impact resistance was influenced mainly by the latter characteristics ${ }^{46}$, but changes in crystal modification distribution also influence this property. The dependence of modulus and tensile yield stress of the polymers on nucleating agent content was very similar in this study; we show only the latter in Fig. $\mathbf{3}$ to demonstrate the correlation. The effect of solubility is very similar as in the case of the crystallization temperature (see Fig. 1); a slight increase is observed at certain nucleating agent content, at around 1000-2000 ppm. Both modulus and yield stress are dominated basically by the overall crystallinity of the polymer, yield stress increasing with increasing crystallinity. One could draw the conclusions, like many do, that properties are determined only by the crystallinity of the samples, but such a simple conclusion would be quite incorrect as shown earlier ${ }^{21,45}$, because lamella thickness at least should be considered. 


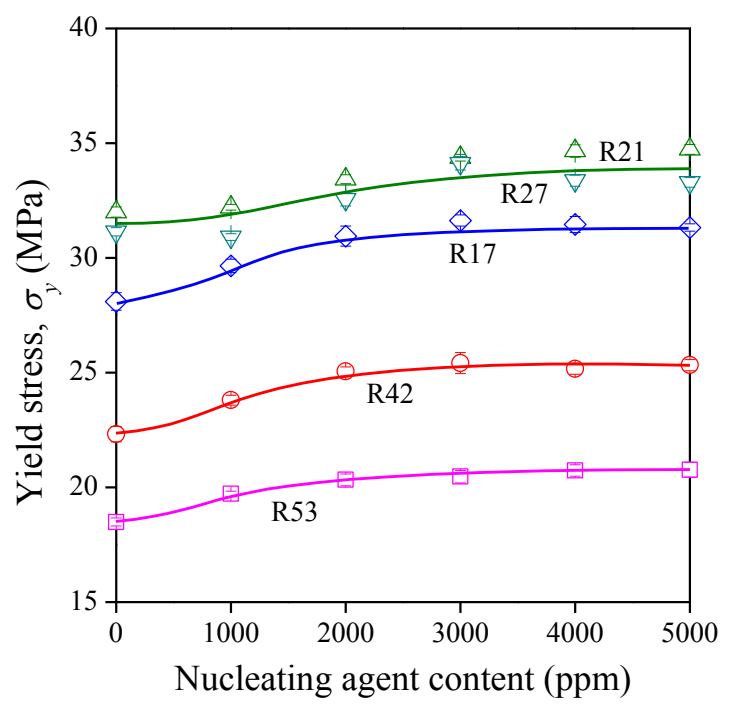

Fig. 3 Dependence of the tensile yield stress of PP random copolymers on the amount of sorbitol nucleating agent added. Symbols: $(\square)$ R53, (O) R42, ( $\nabla)$ R27, ( $\triangle$ ) R21, $(\diamond) \mathrm{R} 17$

Rather surprisingly, the composition dependence of impact resistance is completely different as shown by Fig. 4. At least for the two polymers with the largest ethylene content nucleation results in a significant increase in impact strength, being 200\% for the smaller and $\sim 100 \%$ for the larger MFR material. Impact strength reaches a more or less clear maximum in a medium concentration range, followed by a slight decrease with increasing nucleating agent concentration. The large increase is necessarily initiated by changes in crystalline structure, but cannot be directly related to them, since the size of crystalline units or crystallinity either remained constant or changed only slightly. Small changes in crystalline morphology upon nucleation must have induced the profound modification of molecular mobility or phase structure as suggested by some groups ${ }^{10,15,20,25}$. Further study and analysis is needed to find the decisive factor or process resulting in such drastic changes in impact resistance in the present case. 


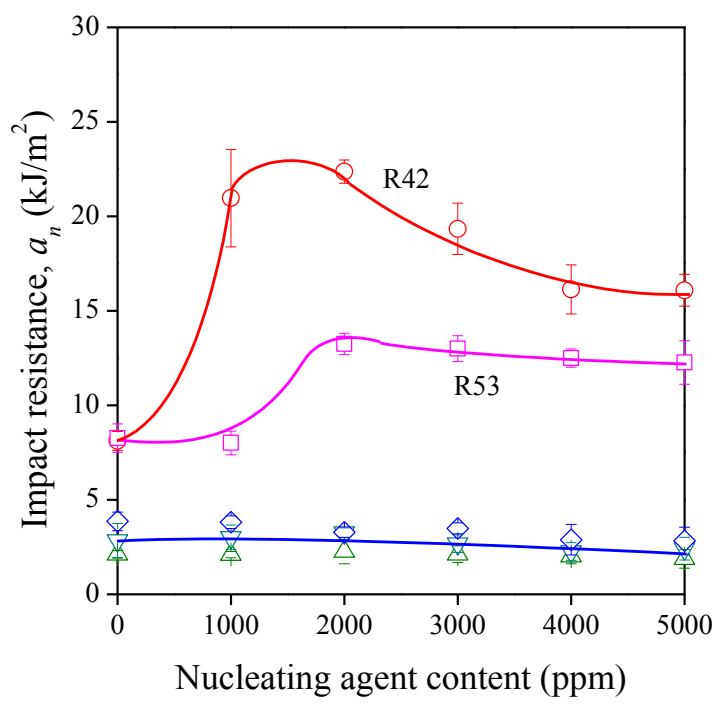

Fig. 4 Effect of nucleation on the impact resistance of PP random copolymers. Nucleating agent: sorbitol. Symbols: $(\square)$ R53, $(\bigcirc)$ R42, $(\nabla)$ R27, $(\triangle)$ R21, ( $\diamond)$ R17

A further confirmation of this drastic change is presented in Fig. 5 in which the stiffness of the samples is plotted against their impact resistance. It is well known and generally accepted that normally an inverse correlation exists between stiffness and impact resistance for structural materials ${ }^{47,48}$. The correlation can be observed also for our materials containing small amounts of ethylene, but strongly deviates from the general tendency upon nucleation for the two polymers with the large ethylene content. It is interesting to note again that ethylene content alone does not determine the extent of deviation. Other structural parameters, like isotactic run length and molecular weight, must also play a role, since the largest deviation from the general tendency is shown by the R42 polymer. 


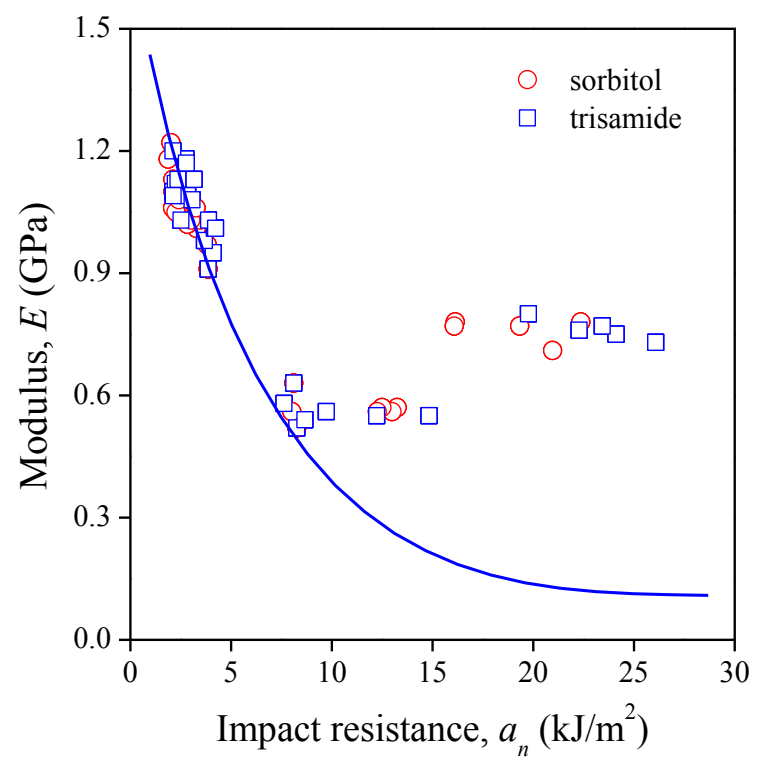

Fig. 5 Stiffness of nucleated random copolymers plotted against their impact resistance. Symbols: $(\bigcirc)$ sorbitol, $(\square)$ trisamide.

\section{Structure-property correlations}

Although apparently a direct relationship cannot be expected between any characteristics of crystalline structure and mechanical properties, we analyzed possible correlations in detail. As mentioned above, modulus is determined by crystallinity and lamella thickness ${ }^{14}$ and the same applies to yield stress. In Fig. 6 the latter quantity is plotted against crystallization temperature proportional to lamella thickness. A very clear correlation exists between the two quantities for all polymers and if we shift the lines vertically according to overall crystallinity, we could obtain a single correlation, just as it was done before for modulus ${ }^{14}$. Since crystallinity practically does not change with nucleation (see Fig. 2) the factor dominating property change is the thickness of the lamellae. The correlations presented in Fig. 6 correspond completely to the expectations and previous experience. 


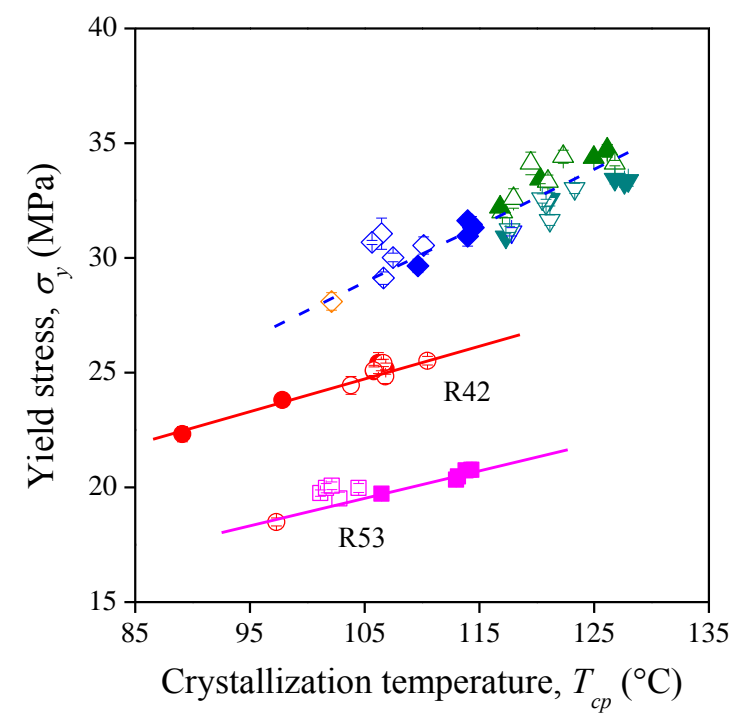

Fig. 6 Correlation between the tensile yield stress and crystallization temperature (lamella thickness) of nucleated PP copolymers. Symbols: $(\square)$ R53, (O) R42, ( $\nabla)$ R27, ( $\triangle$ ) R21, $(\diamond)$ R17. Full: sorbitol; empty: trisamide.

The results presented above are not very surprising, but do not explain the dissimilar correlation obtained for impact resistance (see Fig. 4). Impact strength was plotted against crystallinity (enthalpy of crystallization) and also against $T_{c p}$. The first correlation is presented in Fig. 7. It seems to be quite complicated, but allows the drawing of interesting conclusions. Impact resistance changes in a wide range, but it is practically completely independent of crystallinity. This is not very surprising, since the crystallinity of these samples did not change with increasing nucleating agent content. It is more important, though, that smaller overall crystallinity (R53) is not accompanied by larger impact resistance (R42), i.e. impact strength depends on some other factor as crystallinity. This statement is further corroborated by the correlation obtained for the remaining three polymers (R17, R21, R27). The enthalpy of crystallization changes in a relatively narrow, but definitely wider range than for the other two polymers (R42, R53), from 76 to $91 \mathrm{~J} / \mathrm{g}$, and impact resistance, which is very small for these polymers anyway, further decreases with increasing crystallinity. We can conclude from 
these results that the general tendency showing that fracture resistance decreases with increasing crystallinity is valid at small ethylene content, but does not prevail at larger comonomer content and/or at larger molecular weight.

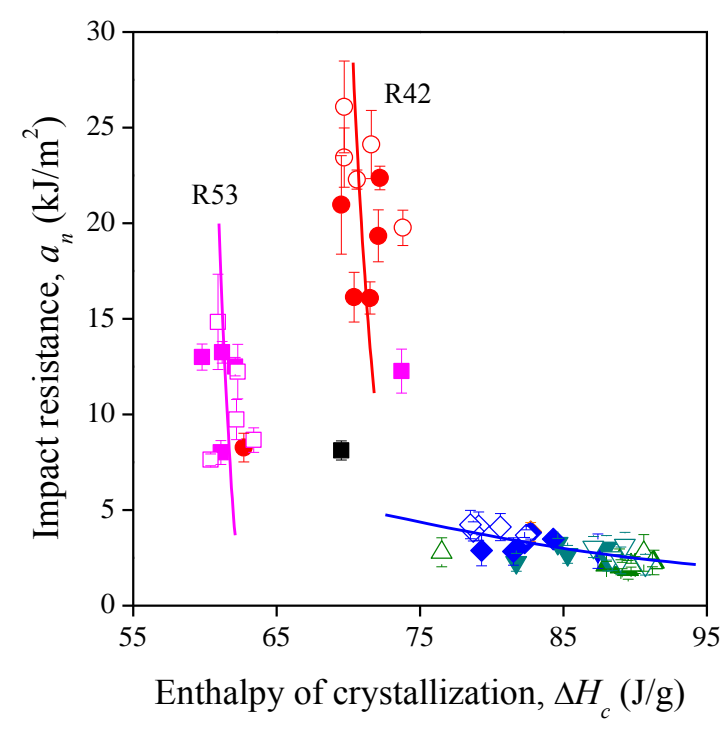

Fig. 7 Lack of correlation between the impact resistance of nucleated random copolymers and their crystallinity (enthalpy of crystallization). Symbols: ( $\square$ ) R53, $(\bigcirc)$ R42, $(\nabla)$ R27, $(\triangle)$ R21, $(\diamond)$ R17. Full: sorbitol; empty: trisamide.

Impact resistance is plotted against the peak temperature of crystallization which is proportional to lamella thickness ${ }^{21}$ in Fig. 8. We obtain three correlations again, two separate ones for the polymers containing large amount of ethylene and another one for the rest. The correlations are very clear; impact resistance decreases with increasing lamella thickness and it has a definite effect on impact resistance. We must emphasize here, however, that inverse correlations have been obtained, i.e. impact strength decreases with increasing lamella thickness, which seems to be rather contradictory, since nucleation increases lamella thickness and it led to the drastic increase of impact resistance at least for the two polymers with large ethylene content. The contradiction can be resolved if we assume that the increase in lamella 
thickness induces some structural change which finally results in the observed changes in impact resistance, or other modifications also occur in morphology, which do not appear in the overall characteristics of crystalline structure determined by DSC $\left(T_{c}, \Delta H_{c}\right)$.

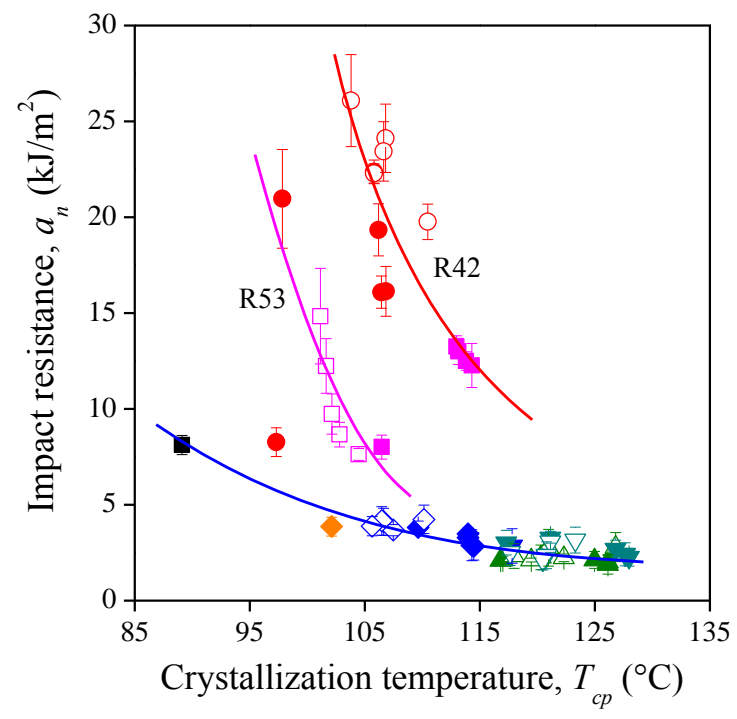

Fig. 8 Correlation between the impact resistance and crystallization temperature of nucleated PP random copolymers. Symbols: $(\square)$ R53, $(\bigcirc)$ R42, $(\nabla)$ R27, ( $\triangle)$ R21, $(\diamond)$ R17. Full: sorbitol; empty: trisamide.

\section{Fracture analysis}

The fracture process can be divided into two steps: Crack initiation and propagation. Polymer structure determines both processes, and nucleation might modify morphology in a way which changes either one of them or both. Instrumented impact testing was carried out to analyze the effect of nucleation on the fracture process. Traces obtained for the R42 polymer nucleated with the trisamide compound are presented in Fig. 9. The considerable effect of nucleation is obvious at first glance. The maximum force, i.e. initiation, increases slightly, but 
the area under the traces is much larger for nucleated samples than for the neat polymer. It appears that the change in morphology initiated by nucleation influences crack propagation much more than initiation. Similar traces were recorded for the same polymer nucleated by the sorbitol clarifier, but practically no changes or very slight ones could be detected in fractograms recorded on the three polymers with small ethylene content (R17, R21, R27).

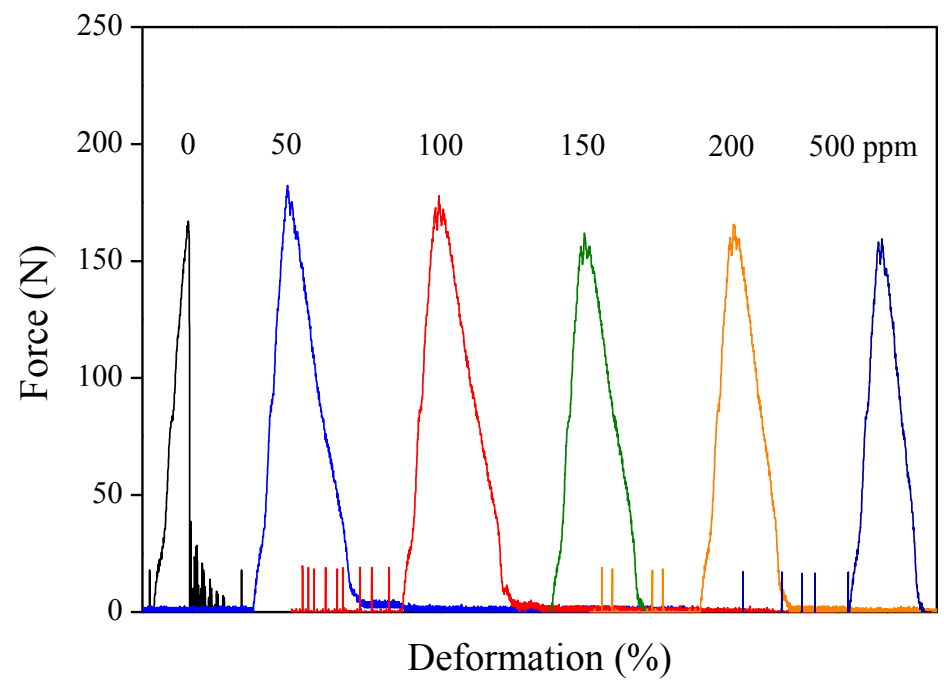

Fig. 9 Effect of nucleation on the fracture of notched specimens prepared from the R42 PP copolymer. Nucleating agent: trisamide.

The maximum force at initiation is plotted against nucleating agent content in Fig. 10. The qualitative conclusions obtained by the direct inspection of primary traces (see Fig. 9) are strongly confirmed by the correlations presented. Maximum force increases slightly with increasing nucleating agent content for four of the polymers, but the increase is very small indeed and the values obtained are very similar for all four. 


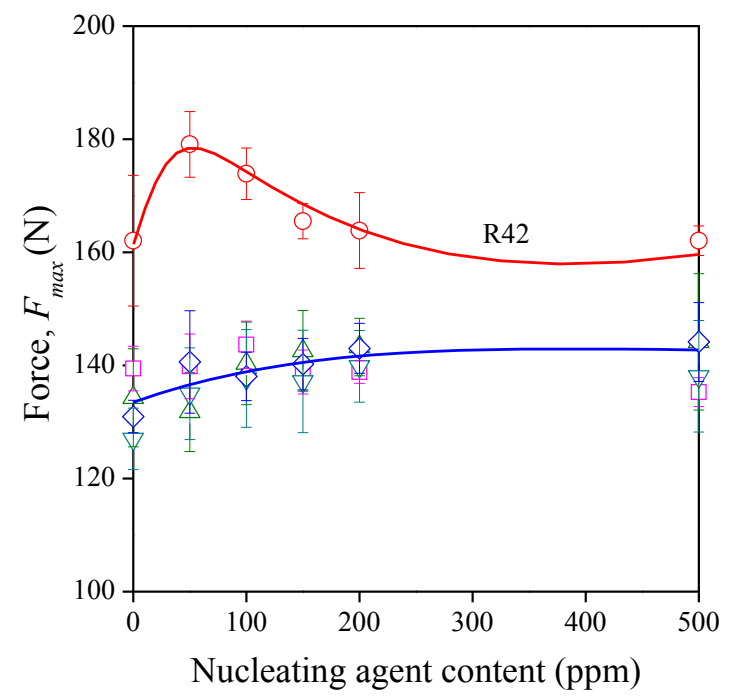

Fig. 10 Effect of nucleation on crack initiation $\left(F_{\max }\right)$ during the fracture of notched specimens prepared from nucleated PP copolymers. Symbols: ( $\square$ ) R53, (O) R42, $(\nabla) \mathrm{R} 27,(\triangle) \mathrm{R} 21,(\diamond) \mathrm{R} 17$. Nucleation: trisamide.

Somewhat larger values and a maximum are obtained for the R42 polymer indicating that structural changes caused by nucleation hinder fracture initiation. Fracture energy, i.e. the area under the traces changes much more drastically and the differences among the polymers are much larger (Fig. 11). Moreover, the correlations are very similar to those obtained for standard notched Charpy impact resistance (Fig. 4) indicating that the latter is determined by the energy needed for the propagation of the crack. 


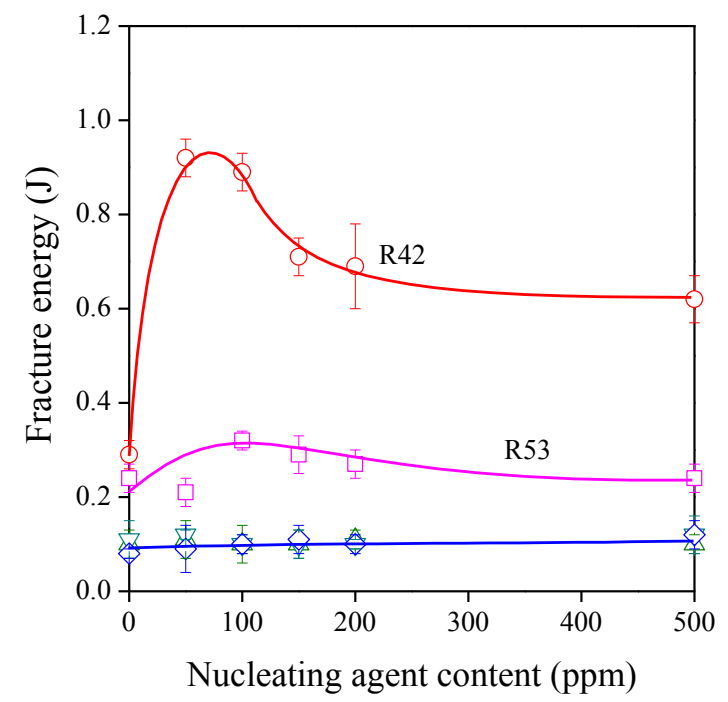

Fig. 11 Fracture energy determined by instrumented impact testing plotted against the nucleating agent content of PP random copolymers containing the trisamide compound. Symbols: $(\square)$ R53, $(\bigcirc)$ R42, ( $\nabla)$ R27, $(\triangle)$ R21, $(\diamond)$ R17. Nucleation: trisamide.

\section{Analysis of morphology, discussion}

Since earlier experience and also the conclusions drawn in previous sections indicate that increasing crystallinity and lamella thickness results in decreasing fracture resistance, we must assume that nucleation induces the rearrangement of the phases or some changes in the mobility of amorphous molecules as proposed by some groups ${ }^{15,20}$. We therefore carried out a dynamic mechanical analysis of the samples. Three transitions could be identified in all traces with varying intensities. The one appearing at the lowest temperature, at around $-60{ }^{\circ} \mathrm{C}$ is very weak and it is related to the relaxation transition of the EP copolymer units of the polymer. The second observed at around $0{ }^{\circ} \mathrm{C}$ is assigned to the amorphous PP phase, while the third at $50-90{ }^{\circ} \mathrm{C}$ to the interphase between the amorphous and crystalline phases of $\mathrm{PP}^{16}$. Nucleation 
induces only very slight changes in the DMA spectra of the polymer (demonstrated in Figure S1). A small shift was observed in the position of transition temperatures and the intensity of the peaks also seemed to change as an effect of nucleation. However, detailed analysis of all spectra did not confirm significant changes in either quantity, both the intensity and the position of the transitions proved to be independent of the amount of nucleating agent or slight shifts occurred in them at most. As a consequence, we could not confirm significant modification in molecular mobility justifying the large increase observed in impact resistance upon nucleation, and even the shifts in transition temperatures indicated the opposite, a decrease in mobility instead of the expected increase.

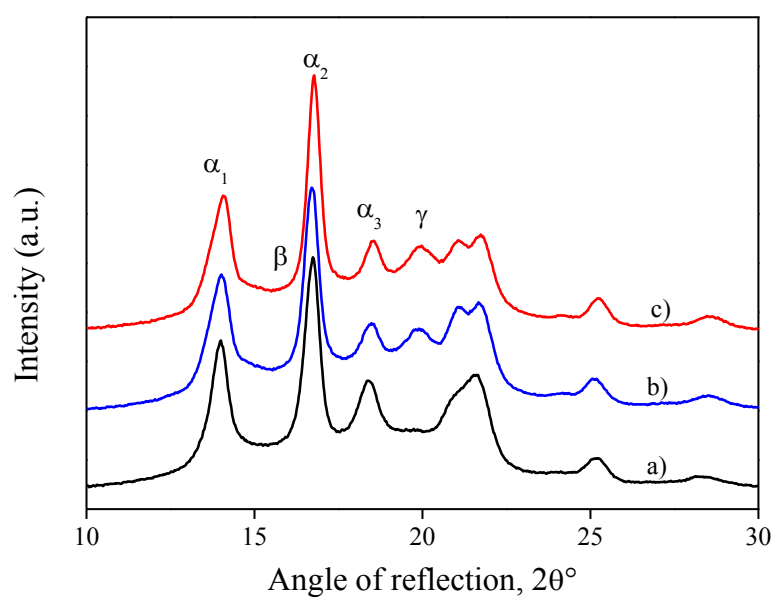

Fig. 12 Effect of nucleation on the local morphology. Increase in the amount of the $\gamma$ modification of PP upon nucleation. R42 copolymers; a) neat, b) 2000 ppm, c) 4000 ppm sorbitol nucleating agent.

The analysis of DSC results showed practically constant crystallinity and an increase in lamella thickness $\left(T_{c}\right)$ with increasing nucleating agent content for the two polymers with large ethylene content. This increase could not be related directly to the observed large increase in impact resistance. XRD measurements and the detailed analysis of the traces, however, indicated interesting changes in local morphology. The XRD traces presented in 
Fig. 12 show the domination of the $\alpha$ crystal form of PP, traces of $\beta$ PP and surprisingly large amount of the $\gamma$-phase around $20^{\circ}$ of $2 \theta$. Obviously, nucleation facilitates the formation of this crystal form of PP. Quantitative analysis of crystal orientation indicated an increase in orientation not only in the skin, but also in the core of the specimens. Herman's orientation factor, $f_{c}$, increased from 0.088 to 0.144 in the R42 polymer at 2000 ppm sorbitol content. Such large orientation in the core is unusual and might be related to a decrease in relaxation time due to the fast crystallization in the polymers with large ethylene content (see also $\Delta T_{c}=$ $\left.18^{\circ} \mathrm{C}\right)$.

A SEM study confirmed local changes in morphology even further. Typical micrographs are presented in Fig. 13 to demonstrate the effect. Potassium permanganate etching oxidizes away the dispersed EP and the amorphous PP phase. The micrograph prepared from the neat R42 polymer shows a relatively smooth surface with some pits and holes indicating the removal of the two amorphous phases by etching (Fig. 13a). Lamellae cannot be identified in the micrograph practically at all. Nucleation changes morphology considerably. Both the size and the depths of the holes increase in the nucleated sample having impact resistance close to the maximum. Besides increased lamella thickness and orientation, the formation of shish-kebab structures can also be observed definitely in the core which is quite unusual; the kebab-part lamellae vertical to the flow direction are indicated by circles in Fig. 13c. The appearance of pronounced and thick lamellae corroborates previous analysis and results, which show that increasing lamella thickness leads to decreasing fracture resistance. The maximum in impact strength can also be explained by this observation; nucleation induces a certain local rearrangement of morphology in the copolymers, including increased lamella thickness and orientation, results in a drastic increase in impact resistance, which then continuously decreases at larger nucleating agent contents due to increasing lamella thickness. 


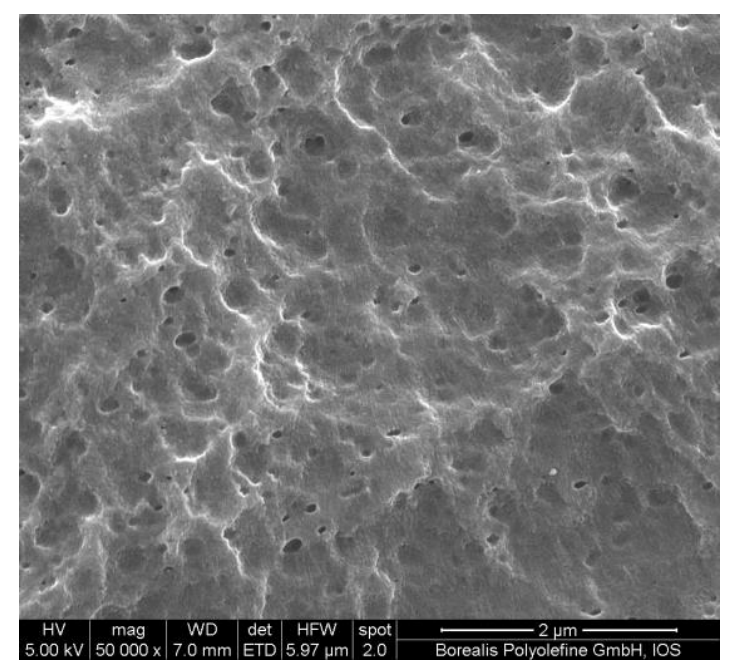

a)

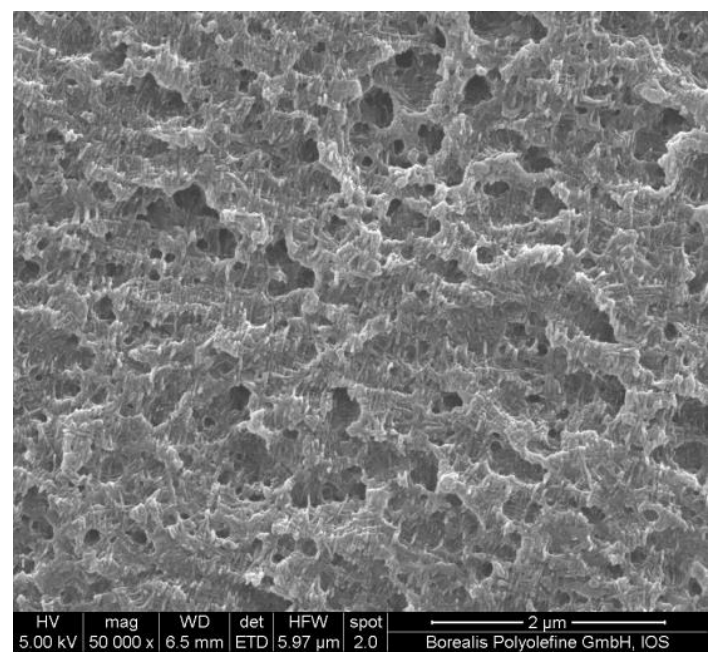

b)

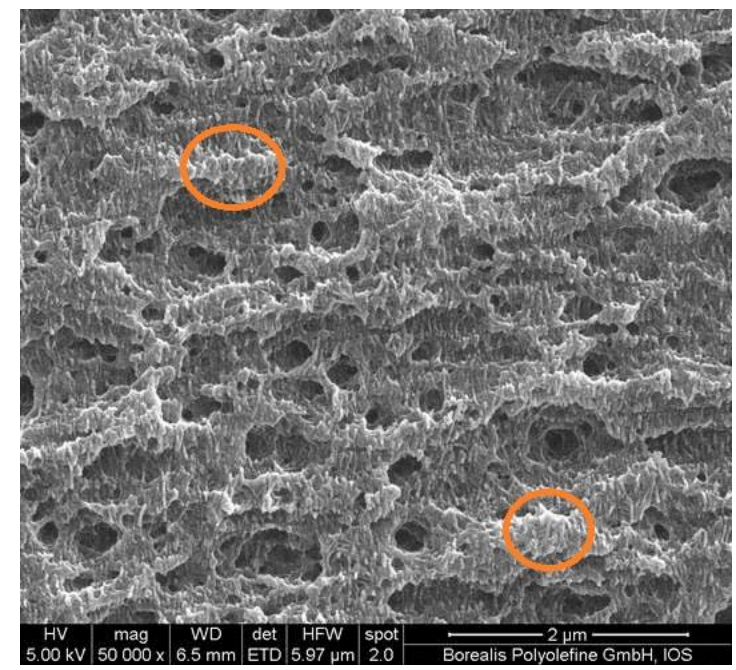

c)

Fig. 13 SEM micrographs taken from the etched cryo-cut surface of samples taken from the core area of selected PP specimens. a) neat R42 polymer, without nucleating agent, b) R42, 2000 ppm sorbitol, c) R42, 4000 ppm sorbitol.

\section{CONCLUSIONS}

The study of the effect of nucleation on the mechanical properties of polypropylene random copolymers with various ethylene content showed that most properties change moderately, but impact resistance increases considerably above a certain ethylene content. A detailed analysis of crystalline structure proved that crystal modification and crystallinity 
changed only slightly, while lamella thickness increased as a result of nucleation. Spherulitic structure was not detected, a microcrystalline structure formed in the presence of the soluble nucleating agents used. The large increase in impact resistance could not be related directly to changes in crystalline morphology. On the other hand, local rearrangement of morphology was detected by XRD and SEM analysis confirming the increase of lamella thickness, but also increased crystal orientation and the formation of shish-kebab structures in the core of the injection molded specimens. A small increase in the $\gamma$-phase content of PP was also observed. These changes increased crack propagation energy considerably leading to the large improvement observed in impact resistance. Although the phenomenon could be related to ethylene content, differences in comonomer concentration alone do not explain the extent of the changes. The results obtained in this study prove that proper design of the molecular structure of polypropylene makes possible the production of high impact compounds without the use of additional elastomer impact modifier.

\section{ACKNOWLEDGEMENTS}

The authors acknowledge the support of the National Scientific Research Fund of Hungary (OTKA Grant No K 101124 and PD 109346) for this project on the structureproperty correlations of polymeric materials. One of the authors (Alfréd Menyhárd) should like to express his gratitude to the János Bolyai Research Scholarship of the Hungarian Academy of Sciences for its financial support. Special thanks go to Davide Tranchida of the APOC services at Borealis Linz for his help with X-ray analysis and interpretation.

\section{REFERENCES}

1. Gahleitner, M.; Paulik, C. In Ullmann's Encyclopedia of Industrial Chemistry; WileyVCH Verlag GmbH \& Co. KGaA: Weinheim, 2014.

2. Moore, E. P., Ed. Polypropylene Handbook: Polymerization, Characterization, Properties, Processing, Applications, Hanser-Gardner Publications: Cincinnati, 1996.

3. Karger-Kocsis, J., Ed. Polypropylene: Structure, Blends and Composites, Chapmann\&Hall: London, 1995.

4. $\quad$ Stern, C.; Frick, A.; Weickert, G., J. Appl. Polym. Sci. 103, 5192007.

5. $\quad$ Paulik, C.; Gahleitner, M.; Neissl, W., Kunstst.-Plast Eur. 86, 11441996.

6. $\quad$ Starke, J. U.; Michler, G. H.; Grellmann, W.; Seidler, S.; Gahleitner, M.; Fiebig, J.; Nezbedova, E., Polymer 39, 751998.

7. Wu, S. H., Polym. Eng. Sci. 30, 7531990. 
8. Doshev, P.; Kheirandish, S.; Pukánszky, B.; Menyhárd, A.; Gahleitner, M.; Borealis: 2011.

9. Doshev, P.; Martin-Luther University Halle-Wittenberg, Aachen: 2005, p 131.

10. Gahleitner, M.; Wolfschwenger, J.; Bachner, C.; Bernreitner, K.; Neissl, W., J. Appl. Polym. Sci. 61, 6491996.

11. Salazar, A.; Rico, A.; Rodriguez, S.; Navarro, J. M.; Rodriguez, J., Polym. Eng. Sci. 52, 8052012.

12. Gahleitner, M.; Jääskeläinen, P.; Ratajski, E.; Paulik, C.; Reussner, J.; Wolfschwenger, J.; Neissl, W., J. Appl. Polym. Sci. 95, 10732005.

13. Busse, K.; Kressler, J.; Maier, R. D.; Scherble, J., Macromolecules 33, 87752000.

14. Gahleitner, M.; Tranninger, C.; Doshev, P., J. Appl. Polym. Sci. 130, 30282013.

15. Na, B.; Li, Z.; Lv, R.; Zou, S., Polym. Eng. Sci. 52, 8932012.

16. Gahleitner, M.; Fiebig, J.; Wolfschwenger, J.; Dreiling, G.; Paulik, C., J. Macromol. Sci. Part B-Phys. B41, 8332002.

17. Chen, J.-w.; Dai, J.; Yang, J.-h.; Huang, T.; Zhang, N.; Wang, Y., Journal of Materials Research 28, 31002013.

18. van Reenen, A. J.; Basson, N. C., Express Polym. Lett. 6, 4272012.

19. Li, K.; Huang, H.-X., Polym. Eng. Sci. 52, 21572012.

20. Li, X. Y.; Wang, K.; Fu, Q., Polym. Eng. Sci. 53, 20532013.

21. Pukánszky, B.; Mudra, I.; Staniek, P., J. Vinyl Add. Tech. 3, 531997.

22. Grein, C., Advances in Polymer Science 188, 432005.

23. Varga, J., J. Macromol. Sci. Part B-Phys. B41, 11212002.

24. Fanegas, N.; Gomez, M. A.; Jimenez, I.; Marco, C.; Garcia-Martinez, J. M.; Ellis, G., Polym. Eng. Sci. 48, 802008.

25. Grein, C.; Gahleitner, M., Express Polym. Lett. 2, 3922008.

26. Horváth, Z.; Menyhárd, A.; Doshev, P.; Gahleitner, M.; Vörös, G.; Varga, J.; Pukánszky, B., ACS Applied Materials \& Interfaces 6, 74562014.

27. Horváth, Z.; Menyhárd, A.; Doshev, P.; Gahleitner, M.; Tranninger, C.; Kheirandish, S.; Varga, J.; Pukánszky, B., J. Appl. Polym. Sci. 130, 33652013.

28. Horváth, Z.; Gyarmati, B.; Menyhárd, A.; Doshev, P.; Gahleitner, M.; Varga, J.; Pukánszky, B., RSC Advances 4, 197372014.

29. Garoff, T.; Virkkunen, V.; Jääskeläinen, P.; Vestberg, T., Eur. Polym. J. 39, 1679 2003.

30. Gahleitner, M.; Grein, C.; Kheirandish, S.; Wolfschwenger, J., Int. Polym. Proc. 26, 2 2011.

31. Abraham, F.; Ganzleben, S.; Hanft, D.; Smith, P.; Schmidt, H. W., Macromol. Chem. Phys. 211, 1712010.

32. Kluge, D.; Singer, J. C.; Neubauer, J. W.; Abraham, F.; Schmidt, H. W.; Fery, A., Small 8, 25632012.

33. Romankiewicz, A.; Sterzynski, T., Macromolecular Symposia 180, 2412002.

34. Brückner, S.; Meille, S. V.; Petraccone, V.; Pirozzi, B., Prog. Polym. Sci. 16, 361 1991.

35. Horváth, Z.; Menyhárd, A.; Doshev, P.; Gahleitner, M.; Varga, J.; Tranninger, C.; Pukánszky, B., J. Therm. Anal. Calorim. 118, 2352014.

36. Menyhárd, A.; Gahleitner, M.; Varga, J.; Bernreitner, K.; Jääskeläinen, P.; Řysćd, H.; Pukánszky, B., Eur. Polym. J. 45, 31382009.

37. Thierry, A.; Straupe, C.; Wittmann, J. C.; Lotz, B., Macromolecular Symposia 241, 1032006.

38. Ouederni, M.; Phillips, P. J., J. Polym. Sci. Pt. B-Polym. Phys. 33, 13131995.

39. Nitta, K. H.; Takayanagi, M., J. Polym. Sci. Pt. B-Polym. Phys. 37, 3571999. 
40. Pawlak, A.; Galeski, A.; Rozanski, A., Prog. Polym. Sci. 39, 9212014.

41. Seguela, R., J. Polym. Sci. Pt. B-Polym. Phys. 43, 17292005.

42. Takayanagi, M.; Nitta, K.; Kojima, O., J. Macromol. Sci. Part B-Phys. B42, 1049 2003.

43. Uehara, H.; Matsuda, H.; Aoike, T.; Yamanobe, T.; Komoto, T., Polymer 42, 5893 2001.

44. Men, Y. F.; Rieger, J.; Lindner, P.; Enderle, H. F.; Lilge, D.; Kristen, M. O.; Mihan, S.; Jiang, S. C., J. Phys. Chem. B 109, 166502005.

45. Menyhárd, A.; Suba, P.; László, Z.; Fekete, H. M.; Mester, Á. O.; Horváth, Z.; Vörös, G.; Varga, J.; Móczó, J., Express Polym. Lett. 9, 3082015.

46. van der Meer, D. W.; Pukánszky, B.; Vancsó, G. J., J. Macromol. Sci. Part B-Phys. B41, 11052002.

47. Keledi, G.; Sudár, A.; Burgstaller, C.; Renner, K.; Móczó, J.; Pukánszky, B., Express Polym. Lett. 6, 2242012.

48. Ashby, M. F.; Jones, D. R. H. In Engineering Materials 2 (Fourth Edition); Jones, M. F.; Ashby, D. R. H., Eds.; Butterworth-Heinemann: Boston, 2013. 


\section{TABLE}

Table 1 Molecular characteristics of the polymers used in the study

\begin{tabular}{|c|c|c|c|c|c|c|}
\hline \multirow[t]{2}{*}{ Polymer } & \multirow{2}{*}{$\begin{array}{l}\text { Et content } \\
(\mathrm{wt} \%)\end{array}$} & \multirow{2}{*}{$\begin{array}{c}\text { I run length }^{\mathrm{a}} \\
\text { (m.u.) }\end{array}$} & \multicolumn{2}{|c|}{ Molecular mass $(\mathrm{kg} / \mathrm{mol})$} & \multirow[t]{2}{*}{$M_{w} / M_{n}$} & \multirow{2}{*}{$\begin{array}{c}\text { MFR } \\
\text { (g/10 min) }\end{array}$} \\
\hline & & & $M_{n}$ & $M_{w}$ & & \\
\hline R17 & 1.7 & 33.9 & 77 & 211 & 2.7 & 8.0 \\
\hline R21 & 2.1 & 41.0 & 40 & 217 & 5.4 & 14.0 \\
\hline R27 & 2.7 & 50.3 & 44 & 195 & 4.5 & 15.0 \\
\hline $\mathrm{R} 42$ & 4.2 & 32.1 & 85 & 317 & 3.7 & 1.5 \\
\hline R53 & 5.3 & 29.4 & 60 & 195 & 3.2 & 12.0 \\
\hline
\end{tabular}

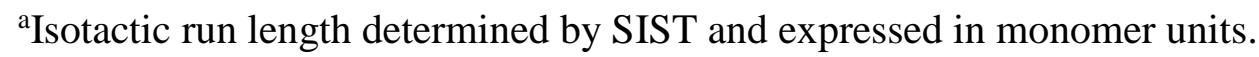

\section{CAPTIONS}

Fig. 1 Effect of the molecular structure of the polymer and nucleation on the peak temperature of crystallization of PP random copolymers containing the sorbitol clarifier. Symbols: $(\square)$ R53, $(\bigcirc)$ R42, $(\nabla)$ R27, $(\triangle)$ R21, $(\diamond)$ R17

Fig. 2 Enthalpy of crystallization plotted against the concentration of the sorbitol nucleating agent for polymers with various ethylene contents. Symbols: ( $\square$ ) R53, $(\bigcirc) \mathrm{R} 42,(\nabla) \mathrm{R} 27,(\triangle) \mathrm{R} 21,(\diamond) \mathrm{R} 17$

Fig. 3 Dependence of the tensile yield stress of PP random copolymers on the amount of sorbitol nucleating agent added. Symbols: $(\square)$ R53, (○) R42, ( $\nabla)$ R27, ( $\triangle$ ) R21, $(\diamond) \mathrm{R} 17$

Fig. 4 Effect of nucleation on the impact resistance of PP random copolymers.

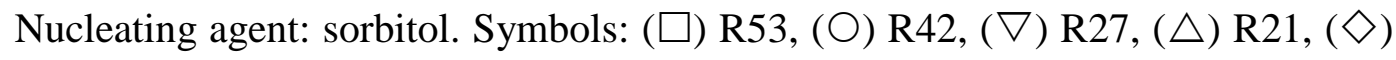
R17

Fig. 5 Stiffness of nucleated random copolymers plotted against their impact resistance. Symbols: $(\bigcirc)$ sorbitol, $(\square)$ trisamide.

Fig. 6 Correlation between the tensile yield stress and crystallization temperature (lamella thickness) of nucleated PP copolymers. Symbols: ( $\square$ ) R53, (O) R42, $(\nabla)$ R27, $(\triangle)$ R21, $(\diamond)$ R17. Full: sorbitol; empty: trisamide.

Fig. 7 Lack of correlation between the impact resistance of nucleated random copolymers and their crystallinity (enthalpy of crystallization). Symbols: ( $\square$ ) R53, 
$(\bigcirc)$ R42, $(\nabla)$ R27, $(\triangle)$ R21, $(\diamond)$ R17. Full: sorbitol; empty: trisamide.

Fig. 8 Correlation between the impact resistance and crystallization temperature of nucleated PP random copolymers. Symbols: $(\square)$ R53, $(\bigcirc)$ R42, ( $\nabla)$ R27, ( $\triangle)$ R21, $(\diamond)$ R17. Full: sorbitol; empty: trisamide.

Fig. 9 Effect of nucleation on the fracture of notched specimens prepared from the R42 PP copolymer. Nucleating agent: trisamide.

Fig. 10 Effect of nucleation on crack initiation $\left(F_{\max }\right)$ during the fracture of notched specimens prepared from nucleated PP copolymers. Symbols: $(\square)$ R53, (O) R42, $(\nabla) \mathrm{R} 27,(\triangle) \mathrm{R} 21,(\diamond) \mathrm{R} 17$. Nucleation: trisamide.

Fig. 11 Fracture energy determined by instrumented impact testing plotted against the nucleating agent content of PP random copolymers containing the trisamide compound. Symbols: ( $\square)$ R53, ( $)$ R42, ( $\nabla)$ R27, ( $\triangle)$ R21, ( $\diamond)$ R17. Nucleation: trisamide.

Fig. 12 Effect of nucleation on the local morphology. Increase in the amount of the $\gamma$ modification of PP upon nucleation. R42 copolymers; a) neat, b) 2000 ppm, c) 4000 ppm sorbitol nucleating agent.

Fig. 13 SEM micrographs taken from the etched cryo-cut surface of selected PP specimens. The slices were cut from the core of injection molded specimens parallel to flow direction. a) neat R42 polymer, without nucleating agent, b) R42, 2000 ppm sorbitol, c) R42, 4000 ppm sorbitol.

\section{GRAPHICAL ABSTRACT}

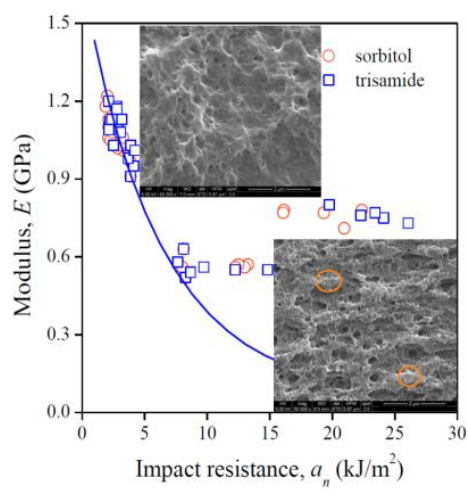

